Jurnal DISASTRI (Pendidikan Bahasa dan Sastra Indonesia)

Volume 2, Nomor 3, Desember 2020| P-ISSN : 2716-4114 | E-ISSN: 2722-3329

\title{
NOVEL DIBALIK SENJA BY MOH. RIFA'I (A STUDY OF LITERATURE ECOLOGY)
}

\author{
Sally Andriani Wukalen ${ }^{1,}$ Haris Supratno ${ }^{2}$, Indah Mei Diastuti ${ }^{3}$ \\ ${ }^{1,3}$ Fakultas Ilmu Pendidikan, Universitas Hasyim Asy'ari \\ ${ }^{2}$ Universitas Negeri Surabaya
}

Corresponding Author: ${ }^{\mathbf{1}}$ sallyandriani20@gmail.com

\begin{abstract}
Abstact
The purpose of this research is to described environmental damage damage the environment, protection of the universe and the impact of environmental recovery in novel Di Balik Senja by Moh Rifai. Research qualitative study used descriptive qualitative type methods. Primary data the come of novels Di Balik Senja Karya Moh Rifai. Analysis technique using qualitative analysis descriptive reviews ecology literary environmental destruction, covering damage the environment, maintenance and the impact environment environment maintenance. Based on the research other it can be concluded some respects between the environmental damage in in a novel Di Balik Senja Karya Moh Rifai, the on landslides, maintenance with mountain environment namely set sojol be forest heritage, nature and the impact the habitats of flora and fauna maintenance back to good.
\end{abstract}

Keyword: Novel, di balik senja, ecology literature.

\section{NOVEL DI BALIK SENJA KARYA MOH. RIFA'I (SEBUAH KAJIAN EKOLOGI SASTRA)}

\begin{abstract}
Abstrak
Tujuan penelitian ini yaitu untuk mendeskripsikan kerusakan lingkungan, dampak kerusakan lingkungan, perlindungan alam semesta dan dampak pemulihan lingkungan yang ada di dalam novel Di Balik Senja Karya Moh Rifai . Penelitian ini menggunakan jenis penelitian kualitatif, metode deskriptif kualitatif. sumber data primer dalam penelitian ini berasal dari novel Di Balik Senja karya Moh Rifai. Teknik analisa menggunakan analisa deskriptif kualitatif tentang tinjauan ekologi sastra yang meliputi kerusakan lingkungan, dampak kerusakan lingkungan, pemeliharaan lingkungan dan dampak pemeliharaan lingkungan. Berdasarkan hasil penelitian dapat disimpulkan beberapa hal antara lain Kerusakan lingkungan di dalam novel Di Balik Senja karya Moh Rifai yaitu hutan yang gundul, tanah longsor, pemeliharaan lingkungan yaitu dengan ditetapkan Gunung Sojol menjadi cagar alam dan hutan lindung, dampak pemeliharaan yaitu habitat flora dan fauna kembali menjadi baik.
\end{abstract}

Kata kunci: Novel, di balik senja, ekologi sastra.

\section{PENDAHULUAN}

Karya sastra adalah suatu produk ciptaan seseorang sastrawan, pada dalamnya terdapat yang ingin disampaikan kepada pembacanya. Karya sastra ditulis atau diciptakan sang sastrawan bukan buat dibaca sendiri, melainkan ada wangsit, gagasan, pengalaman, dan amanat yg ingin disampaikan pada

Novel Di Balik Senja ...| 118 
Jurnal DISASTRI (Pendidikan Bahasa dan Sastra Indonesia)

Volume 2, Nomor 3, Desember 2020| P-ISSN : 2716-4114 | E-ISSN: 2722-3329

pembaca. dengan harapan, apa yg disampaikan itu menjadi masukan, sehingga pembaca bisa merogoh konklusi dan menginterpretasikannya menjadi sesuatu yg bisa bermanfaat bagi perkembangan hidupnya. Hal ini bisa menandakan bahwa karya sastra bisa menyebarkan kehidupan serta kebudayaan rakyat. oleh sebab itu sastra bisa dikatakan menjadi cerminan dan ungkapan kehidupan seseorang. Sastra berkaitan erat dengan semua aspek manusia dan alam menggunakan keseluruhannya. Sastra juga membagikan aneka macam imajinasi tadi pada dalam bentuknya sebagai karya sastra. Sastra dalam kehidupan rakyat sangat dibutuhkan, sebab sastra mengandung unsur keindahan tersendiri pada balik cerita kehidupan. Kehidupan masyarakat menggunakan berbagai polemik yang terjadi waktu ini tak menutup kemungkinan buat dituangkan ke dalam karya-karya sastra sehingga menjadi cerminan rakyat itu sendiri.

Konsep-konsep yang terkait perihal ekokritik, sebagai berikut: (a) pencemaran (pollution), hutan belantara (wilderness), mala (apocalypse), perumahan/rumah (dwelling), hewan (animals), dan bumi (earth).

Adapun novel pada kembali Senja ini ialah novel ke 2 dari tetralogi Gunung Sojol. 5 anak belia yg senang bertualang di alam bebas: Ahmad, Leo, Dino, Anto, Icank, bertarung nasib pada Gunung Sojol, buat mencapai misi nomor satu dan misi nomor 2 . di sana, mereka menemui hutan yg hampir punah. Pun, simpanse-kera andalan Sulawesi, yg setiap saat bermigrasi berasal kawasan satu ke tempat yang lain, dampak ulah manusia yang Mengganggu hutan.

Sesuai perseteruan kealaman yg ada di dalam novel pada balik Senja, peneliti akan menelaah pada perseteruan korelasi timbal kembali insan dengan alam. Hal ini bisa dipahami melalui perspektif ekologi sastra. Tinjauan konflik ekologi pada karya sastra menjadi penekanan penelitian karena dilandasi beberapa alasan. Pertama, adanya perspektif ekologi tentang permasalahan tokoh pada novel yg mempunyai korelasi spesifik dengan alam. Kealaman yang dimaksudkan berada di Gunung Sojol Sulawesi Tengah, konflik ekologi yg ada pada novel di pulang Senja bukan hanya pertarungan pembalakan, atau kerusakan hutan semata, melainkan permasalahan hubungan timbal kembali insan menggunakan lingkungan. Ketiga, permasalahan ekologi dalam bentuk karya sastra artinya kritik sosial terhadap dunia nyata sebagai akibatnya, problem manusia serta lingkungan yang ada di wilayah Sarongge ini artinya keliru satu bentuk kritik kesusastraan Indonesia mengenai konflik ekologi pada Indonesia.

Berdasarkan uraian latar belakang diatas, maka penulis tertarik meneliti lebih dalam dengan judul penelitian "Kajian Sastra Ekologi (Ekokritik) Terhadap Novel di pulang Senja Karya Moh Rifai.

\section{METODE PENELITIAN}

Penelitian ini menggunakan jenis penelitian kualitatif. Penelitian kualitatif ialah penelitian yang bermaksud buat tahu fenomena perihal apa yang dialami oleh subyek penelitian misalnya sikap, persepsi, motivasi, tindakan serta lain-lain secara 
Jurnal DISASTRI (Pendidikan Bahasa dan Sastra Indonesia)

Volume 2, Nomor 3, Desember 2020| P-ISSN : 2716-4114 | E-ISSN: 2722-3329

holistik serta menggunakan cara deskripsi. Data deskriptif yang dihasilkan berupa istilah-kata tertulis atau mulut asal orangorang dan perilaku yg diamati. (Hermawan serta Amirullah, 2016). asal data penelitian dibagi sebagai dua antara lain

a. sumber data utama, yaitu data yg langsung dikumpulkan sang peneliti (atau petugasnya) dari sumber pertamanya (Arikunto, 2010). Adapun yg menjadi sumber data primer dalam penelitian ini berasal dari novel pada balik Senja karya Moh Rifai. Novel ini diterbitkan di tahun 2012 sang percetakan Pena Nusantara setebal 384 halaman..

b. sumber data skunder, yaitu data yang langsung dikumpulkan oleh peneliti sebagai penunjang dari sumber pertama. bisa jua dikatakan data yang tersusun dalam bentuk dokumen-dokumen. (Arikunto, 2010). pada penelitian ini, data asal berasal literatur dan kitab dan jurnal penelitian terdahulu

Langkah-langkah penyediaan data tersebut adalah sebaga berikut:

a. Menyediakan novel Di Balik Senja karya Moh Rifai

b. Membaca, menandai, dan mencatat data novel

c. Pengodean Data. Kode yang digunakan ialah DBS (Di Balik Senja). Kode ini diikuti dengan huruf yang menunjukkan hubungan manusia dengan alam (MA) dan hubungan alam dengan manusia (AM). d. Reduksi Data

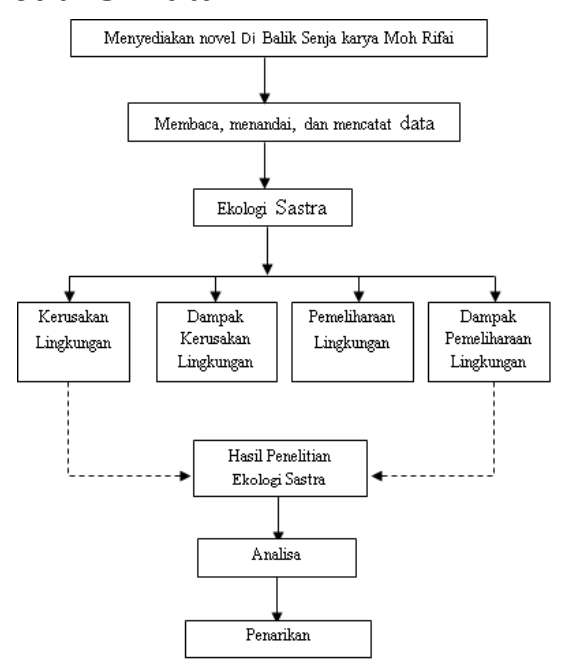

HASIL PENELITIAN DAN PEMBAHASAN

Novel ini menceritakan tentang kegigihan seorang, untuk mencapai sesuatu. Meski duet badai: badai hujan dan badai angin selalu menerpa setiap harinya; meskipun secara fisik sudah tak mampu untuk meneruskan perjalanan; meskipun lutut Ahmad yang keseleo; meskipun di tengah perjalanan menemukan sesuatu yang aneh; meskipun dingin, kabut, binatang buas, selalu mengancam; namun mental mereka selalu hadir dalam setiap jejak langkah di tanah Sojol itu

Novel tersebut, para tokoh yang terdiri dari 5 pemuda Ahmad, Leo, Dino, Anto, dan Icank, menemui hutan yang hampir punah. Pun, monyet-monyet andalan Sulawesi, yang setiap saat bermigrasi dari tempat satu ke tempat yang lain, akibat ulah manusia yang merusak hutan. Kerusakan lingkungna yang ada di Gunung solok antara lain dapat dijelaskan pada petikan tulisan di novel dibalik senja antara lain : 
Jurnal DISASTRI (Pendidikan Bahasa dan Sastra Indonesia)

Volume 2, Nomor 3, Desember 2020| P-ISSN : 2716-4114 | E-ISSN: 2722-3329

"Kerusakan Lingkungan di Gunung Sojol diceritakan terjadi hujan 2x24 jam yang mengakibatkan bajir luar biasa, sebagian tanah-tanah longsor, diterpa banjir bandang, beberapa unit motor, telah hanyut terbawa air bah. Rumah warga banyak yang rusak. Puluhan kepala keluarga mengungsi, ada yang ke rumah keluarga, ada juga yang ke kampung sebelah,. Kebun-kebun, sawah, tanaman, puskesmas, sekolah, masjid, semuanya tergenang air bah setinggi dua meter. Begitu hari sudah mulai sore, hujan mengguyur dari langit. Air semakin menit semakin naik saja. Kekahawatiran warga semakin bertambah. Mereka memikirkan lima anak mudah ditanah Sojol itu." (Rifai, 2018:6)

Penduduk asli berasal Gunung Sojol sendiri artinya suku Dayak, ilustrasi sosok penduduk pedalaman daerah Sojol terus menari-nari di benak pendaki. Sosok bercawat, bersenjata sumpit panjang serta tombak dan sifat buas yg acapkali di dengar semakin menambah kewaspadaan serta keingintahuan yg akbar buat mengungkapnya. "Jea Leang, Mangge!! (Kita mitra)" artinya kalimat yang terpatri di kepala para pendaki saat menuju ke Gunung sojol. Bahasa Laoje atau banyak yang menyebutnya menjadi "bahasa burung" harus kita pelajari buat meredam kebuasan suku ter-asing di pedalaman Sojol. Fuyul (Gunung) Sojol berada di daerah pegunungan Ogoamas, termasuk wilayah Kecamatan sojol utara, Kabupaten Donggala, Propinsi Sulawesi Tengah. Gunung dalam tempat cagar alam ini terletak pada antara sisi barat timur perairan laut Sulawesi
Tengah. untuk mendaki Sojol asal sisi pantai barat, yang akan menjadi awal pendakian ini, ada hambatan buat menerima berita yang akurat. tidak sinkron menggunakan sisi timur yg dilewati jalur trans Sulawesi.

Kerusakan lingkungan yang ada di Gunung solok yang lain juga dijelaskan pada petikan tulisan di novel dibalik senja yaitu :

"Banjir begitu terasa hingga disini. Pengungsi berhamburan kemana-mana. Tak ada jalan lain selain menghindar dari resiko bencana. Bencana yang sebenarnya dibuat oleh manusia. Manusia yang mengakibatkan ini semua. Dan akhirnya, manusia juga yang celaka. Namun bedanya, lain yang berbuat. Lain pula yang menanggungnya. Ini masalah besar. ini yang sudah kita diskusikan beberapa hari lalu. Ternyata, belum juga kita laksanakan rencana kita, bencana sudah mendahului. Orang-orang kampung sana tidak mengetahui, barangkali hutan-hutan mereka di gunung sini, sudah hampir punah semuanya." (Rifai, 2018:16)

Berdasarkan penuturan para tokoh diatas, dapat dijabarkan bahwa, kerusakan lingkungan yang ada di Gunung Solok yaitu hutan yang sudah gundul, atau hampir punah, dengan kondisi tersebut, maka akan mengakibatkan terjadinya banjir dan tanah longsor. Sebuah analisa yang dilakukan oleh tokoh novel yaitu

"pram sudah mengatakan, bahwa jiak bencana itu datangnya dari manusia, maka ia bisa di lawan dengan manusia pula. Artinya kita bisa melawan semua kesewenang-wenangan itu. Bagaimanapun caranya kita libatkan masyarkat terdampak itu. Apalagi, jika perusahaan bijih besi itu, berani 
Jurnal DISASTRI (Pendidikan Bahasa dan Sastra Indonesia)

Volume 2, Nomor 3, Desember 2020| P-ISSN : 2716-4114 | E-ISSN: 2722-3329

memporak-porandakan gunung dan hutan disini, itu bahaya sekali bukan?" (Rifai, 2018:47)

Kondisi alam yang sudah mengalami kerusakan membuat cuaca di kawasan Gunung Sojol juga tidak menentu

"pada malam tak berbintang. Hujan masih saja terus mengguyur bumi Sojol. Guntur masih saja terus meledak-ledak dengan penuh kemarahannya. Petir masih saja menyambar-nyambar pepohonan dengan segala cahayanya yang mengkilat-kilat. Dan angin, masih saja menyapu ersih pohon-pohon dekat, lekat dengan kelima anak muda yang suka berpetualang itu. Ini bukan karunia, menurutku. Atau inikah faktor illegal logging itu. Cuaca selalu saja mengganggu, tak menentu menghadang lima anak manusia. Manusia yang serakah dengan bebasnya ongkang-ongkang kaki di kursi rumahnya, atau pada kantornya, sementara orang-orang di bawah sana, begitu lelah menunggu air akan surut. Dan aku, aku benci dengan kondisiku saat ini. Aku begitu lelah.Jangan salahkan Alam. Biarkan ia merengek rengek sesuai dengna keadaannya. Biarkan dia menghempas kita dengan hukumnya sendiri. Nanti akan kamu dapatkan, apa maksud dari semua ini" (Rifai, 2018:82)

Kondisi lingkungan di kawasan gunung sojol cukup memprihatinkan, bayangkan saja, baru beberapa hari lalu rumah adat di bangun dengan dana hasil swadaya, namun banjir telah membawanya hanyut setengah. Rumah yang tinggi mencapai dua meter itu, menelan puluhan juta rupiah dari hasil gotong royong orang- orang di desa itu. Belum lagi puskesmas yang hanya mempunyai dua bidan itu dindingnya menjadi keropos dibuat banji. Banjir kali ini memamng terhitung ganas, setahun yang lalu banjir tak sedahsyat itu. Sebab, pohon-pohon masih terlihat rapat di area hulu, nah kali ini?

Kerusakan lingkungan di kawasan gunung sojol tidak dirasakan oleh manusia saja, namun juga oleh satwa-satwa yang ada di tempat tersebut, salah satunya adalah monyet

"ia melihat monyet-monyet itu bergelantungan di dahan-dahan pepohonan yang rindang. Monyet andalan sulawesi, makhluk langka sedang bercanda namun tersiksa. Monyet-monyet yang bermain melompat-lompat dari pohon satu ke pohon yang lainnya tanpa takut jatuh. Suara-suara monyet hutan itu terdengan begitu parau. Seolah-olah meminta pertolongan kepada lima pemuda yang suka berpetualang itu" (Rifai, 2018:98)

Dahulu, tempat monyet -monyet itu tak disana, masih jauh dibawah sana, hanya karena hutan mereka di babat habis oleh komprador kota, maka mereka terpaksa pindah lebih jauh ke hulu. Bagaimana jika nanti tempat mereka sekarang itu di babat habis juga?. Bukankah mereka akan punah monyetmonyet andalah Sulawesi itu.

Sebuah dampak lingkungan yang begitu miris membuat psikologi tokoh juga terkena imbasnya. Tubuhnya semakin menggigil, diterpa hujan yang tak pernah berhenti sedetik pun. Ia seolah olah terkulai melengkuklengkuh menyusuir jalanan setapak. Ingin melepaskan diri. Titik-titik hujan masih menyambar tanah tak kenal ampun. Lima pemuda yang suka berpetualang itu 
Jurnal DISASTRI (Pendidikan Bahasa dan Sastra Indonesia)

Volume 2, Nomor 3, Desember 2020| P-ISSN : 2716-4114 | E-ISSN: 2722-3329

merasakan ganasnya alam yang luar biasa. Penetrasi alam meraung-raung di gendang telinga. Hanya itu yang didengar, memekik. Kicauan burung kenari pun tak ada. Sementara serombongan monyet-monyet entah kemana perginya kini

Tidak terasa misi pertama kelima pemuda yang suka berpetualang itu sudah tercapai. Saat Abersi cahanya tiba-tiba muncul dari arah timur. Tepat dimana mata sang pemu pendiam menuju ke arah yang berbinar-binar itu. Alangkah bagusnya di pandang jika pohon pohon itu menyingkir dari tempatnya. Atau angin segera memindahkan kabut dari sana secepat mungkin. Namun biarlah toh abersi cahaya itu akan di jumpai dimana saja. Misi pertama ini tentang mengenal alam semesta. Mengenal diri sendiri, dan mengenal kalian lebih jauh. Dan ini tentang pengendalian diri dari ego dari rakus, dari emosi yang memang di tempah alam tanpa ampun. Kemudian tentang rasa merasa menikmati dan menjaga alam seutuhnya

Kemudian kelima kelima pemuda
yang suka berpetualang memulai
perbincangan untuk memulai misi yang
selanjutnya

" sekarang begini, jika kita tak pernah menginjakkan kaki di gunung ini, apakah kita pernah mengetahui, bahwa ada komunitas yang termarginalkan di sekitar sini? Apakah kita tahu, bahwa hutan-hutan disini sudah hampir punah? Apakah kita tahu flora dan fauna monyet monyet disini sudah terabaikan? Menyadari sewaktu-waktu mereka akan punah. Dan kita akan memperlihatkan kepada dunia, bahwa di balik kabutgunung sojol ini, terdapat monyet khas sulawesi. Apakah kita ketahui semua itu? Aku tahu ini bukan satu keajaiban. Sebab, telah jutaan manusia yang pernah melakukan seperti apa yang kita lakukan saat ini. Namun, percayalah, setiap alam gunung, kondisi objektifnya berbeda beda. Itu yang membedakan gunung sojol dengan gunung-gunung yang lain. Itu juga yang membedakan bahwasanya setiap jejak langkah kita, lumut melekat seperti perangko di telapak kaki sepatu. Dan kita menghadapinya dengan sedikit penuh haru. Jika sewaktu-waktu kita akan mati di gunung ini, yakinlah Tuhan telah tahu bahwa kita telah menginjakkan kaki di tanah tertinggi di Sulawesi Tengah ini Siapa tahu saja demikian. Siapa yang tahu jika penebang pohon yang rakus itu sampai sini sasaran mereka. Siapa tahu kita tak mampu membendung mereka untuk menyelamatkan hutan ini" (Rifai, 2018:116)

Jangan mengira dalam dunia yang fana ini semua serbah murah. Jangan mengira dunia yang semaki liberal ini para kapitalis memperhatikan para buruhnya tau objek yang sedang digarapnya. Tidak. Telah banyak kasus yang dijumpai dalam setiap medan pertempuran para objek dan buruh. Eksploitasi sumber daya alam yang berlebihan. Lihat saja di kampung sana. Orang-orang semua gelisah akibat banjir yang tak pernah surut. Beberapa kerugian yang ditanggung oleh rakyat akibat dari penjajahan hutan yang luar biasa itu? Lihat bagaimana monyetmonyet andalah Sulawesi harus migrasi ke tempat yang semakin jauh. Apa yang 
Jurnal DISASTRI (Pendidikan Bahasa dan Sastra Indonesia)

Volume 2, Nomor 3, Desember 2020| P-ISSN : 2716-4114 | E-ISSN: 2722-3329

dihasilkan oleh periode ini, adalah kerusakan yang luar biasa

"aku benci dengan para pengrusak hutan itu. Kalian tahu, bukan bahwa kita sudah dilingkari oleh hutanhutang yang hampir punah, monyetmonyet juga sudah harus melarikan diri dan komunitasnya lebih jauh dari kampung. Bukan perkara mudah. Yah kawan. Untuk mengusir para pembabat hutan itu, tak semudah menggerak gerakkan kaki saat bersantai di teras rumah. Mereka selalu disokong oleh penguasa. Dan kita tentunya tak perlu lagi terkejut ketika melihat dan mendengan hal itu. Bukanlah sejarah negeri ini penguasa dan pengusaha selalu bersekongkol untuk kepentingan mereka saja. Mereka itu sama sekali tak memikirkan manusia-manusia lai, selain dari bisnisnya. Mereka seolaholah menjadi pencipta bencana, dan masyarakat sekitar menjadi penjemput bencana itu. Hal yang lain adalah penguasa memberikan penghargaan kepada badan hukum mereka yang juga seolah-olah menguntungkan dan bersih dari segala macam akibat"(Rifai, 2018:152)

Kelima pemuda yang suka

berpetualang kemudian berdiskusi tentang sumber kerusakan yang selama ini terjadi

"menurutku sumber dari segala sumber mereka dengan rakus menebang pohon-pohon tanpa ampun itu yaitu legalitas, dan persekongkolan. China dan Vietnam, kedua negara itu yang selama ini menerima kayu-kayu dari Indonesia. Pasar kayu mereka luar biasa, sehingga begitu banyak pemodal dari dalam maupun luar negeri yang membabat hutan di negeri ini. Dan pada enam tahun terakhir, uni Eropa banyak mengimpor kayu-kayu dari Indonesia yang illegal. Nah, jika kita punya lisensi, maka potensi-potensi kerusakan hutan di Indonesia semakin meningkat." (Rifai, 2018:196)

Setelah perbincangan yang cukup serius tersebut, sebuah ide atau solusi diberikan oleh salah satu kelima pemuda yang suka berpetualang

Aku punya ide, bagaimana kalau kita buat stiker, untuk kampanyekan, bahwa hutan disini rusak, kemudian kita bagikan ke orangorang, biar publik tahu dan membantu untuk menyelamatkan hutan di tanah Sojol ini, pun hutan-hutan dilainnya. Untuk biayanya tidak begitu besa, menurutku paling tidak kita buat beberapa buah dulu sebagai langkah awal

Setelah melanjutkan perjalanan menjelajah Kawasan Gunung Sojol kelima pemuda yang suka berpetualang, mendapati lagi hutan di tebang habis, terlihat jelas tanah merah terbuka menganga. Tak ada yang menghalanginya. Pohon-pohon tumbang, ada juga yang tersusun rapi setelah di sensor rapi. Di sekelilingknya pohon-pohon masih ada yang berdiri tegak dan kaku. Diatasnya burung elang melirik sedih tanpa mengepakan sayapnya, dibawahnya aliran air terjun setinggi 30 meter berbunyi keras

"di pohon pohon itu, dilihatnya monyetmonyet berlarian mendengar suara gauman sensor. Mereka berteriak dan seolah -olah mengatakan. Jangan rusak hutanku, hutan yang selama ini begitu nyaman. Nyaman untuk kami mencari makan dan memamabiak. Tolong manusia jangan kau bunyikan lagi mesin perusak hutan itu. Kalian sama sekali tak perdulikan kami. Atau kalin ingin kami

Novel Di Balik Senja ...| 124 
Jurnal DISASTRI (Pendidikan Bahasa dan Sastra Indonesia)

Volume 2, Nomor 3, Desember 2020| P-ISSN : 2716-4114 | E-ISSN: 2722-3329

cakar satu persatu. Mana bos kalian." (Rifai, 2018:201)

Monyet-monyet itu terlihat mengamuk. Namun, mereka tak berdaya akibat ulah manusia serakah itu. Hutan yang rusak itu, sebesar 3 kali lapangan bola versi internasional. Bayangkan saja berapa ribu pohon yang tumbang, ditumbangkan mesin pemotong itu. Bayangkan saja berapa habitat yang akan migrasi ke tempat lain akibat ulah mereka.

Kini, berlahan kelima pemuda yang suka berpetualang turun ke lembah, dan kemudian menanjak lagi hingga ke puncak. Di sana mereka memandang dengan bebas di titik yang rusak itu, suara mesin pemotong sudah tak terdengan lagi dan monyetmonyet Sulawesi sudah tak nampak di pelupuk mata. Rupanya, dibalik anak-anak gunung tersebut, masih ada titik-titik hutan yang rusak. Rusaknya gunung tersebut menyerupai segitiga sama kaki, dua buah sisinya sama panjang, yang lain menyerupai segitiga sembarang, yang ketiga ukuran panjang pada sisinya begitu berbeda. Ditengahnya masih tertancap pohon-pohon. Namun tak seberapa banyaknya. Yang rusak hampir sama dengan ukuran yang titik pertama. Dan monyet-monyet disana juga berteriak-teriak mengamuk. Mereka tak berdaya. Lari terbirit-birit dan ada yang melompat dari pohon satu ke pohon yang lain, menjauh dari kerusakan itu

"Ini bukti ada kerusakan alam, kita bisa melaporkannya, tak usah berlama-lama lagi, mari kita langkahkan kaki kita hingga sampai pada misi nomor dua ini selesai (Rifai, 2018:223)
Kini, kelima pemuda yang suka berpetualang berhenti, berjejer rapi di tepi jurang . melihat sesuatu yang jelas di dapan mak di bawah dan di atas, melepas pandangan jauh, penuh kebebasan. Pesona alam itu berkumandang untuk meminta mereka agar tidak beranjak begitu cepat. Matahari masih menyinari dengan bebasnya pepohonan dibawah sana, sinarnya yang sedikit kemerahmerahan itu membuat monyet menari gembira, namun penuh luka, mereka sedih karena kehilangan tempat tinggalnya. Awan dan kabut sudah tak nampak lagi. Hari ini betul-betul dimana perjuangan menemukan titik kebahagiaan, tapi bukan untuk monyet Sulawesi itu. Ahmad menciptakan puisi di dalam hatinya

"Tuhan ku, aku memohon kepadamu mohon gugah hati manusia yang merusak hugan dan alam-Mu. Mohon gugah hati manusia untuk menyelamatkan hutan dan alam-mu. Tuhanku betapa indah lukisanMu. Aku tahu lukisanMu ini tak pernah tertandingi oleh lukisan manusia manapun dan kiri dua buah mataku yang juga ciptaanMu sedang menikmati ciptaanMu" (Rifai, 2018:243)

Itulah alam. Seharusnya manusia bersahabat dengan alam, dalam diri mausia itu kadang ada yang misterius, rakus dan ambisius. Adalah memandang alam sebagai objek yang pantas dieksploitasi. Ini yang kemudian merubah paradigma berpikir manusia lainnya. Dan ketika manusia lain memandang hal yang sama, maka keserakahan adalah hal yang wajar. Sehingga jika eksploitasi alam itu dilakukan secara 
Jurnal DISASTRI (Pendidikan Bahasa dan Sastra Indonesia)

Volume 2, Nomor 3, Desember 2020| P-ISSN : 2716-4114 | E-ISSN: 2722-3329

berlebihan, maka alam itu akan perih dan mengamuk mensasar manusia.

Hari yang ditungu tungi telah tiba. Hari dimana sejarah akan mencatat. Hari di mana kelima pemuda yang suka berpetualang berjuang mati-maitan untuk menjajakkan telapak kakinya di tanah tertinggi di Sulawesi Tengah . ini petualangan yang tidak main main. Penuh mistis, langit kelabu, dan udara seperti berada di dalam lemari pendingin

\subsection{Pembahasan}

Berdasarkan kajian novel Di balik senja tentang Ekologi Sastra dapat dijabarkan bahwa Kerusakan Lingkungan yang terjadi di Gunung Sojol Sulawesi Tengah adalah hutan gundul, banjir, tanah longsor akibat dari penebangan hutan secara illegal, kerusakan lingkungan yang masif dirasakan tidak hanya oleh manusia saja, flora dan fauna yang mendiami disana, Eksploitasi sumber daya alam yang berlebihan. Kemudian sumber dari segala kerusakan lingkungan ini adalah legalitas, dan persekongkolan.

Solusi yang mencoba ditawarkan dalam novel tersebut untuk mengurangi dampak kerusakan lingkungan yaitu dengan berkampanye bahwa hutan disini rusak, kemudian kita bagikan ke orang-orang, biar publik tahu dan membantu untuk menyelamatkan hutan di tanah Sojol ini, pun hutan-hutan dilainnya.
Penggunaan perspektif ekokritik, novel pada pulang Senja bisa dipahami menjadi galat satu fiksi bernuansa sastra hijau. Novel di pulang Senja mengangkat tema ihwal lokalitas alam daerah Gunung Sojol Sulawesi Tengah, novel ini berbicara wacana konsep Kerusakan lingkungan pada dalam novel di kembali Senja karya Moh Rifai yaitu hutan yg gundul, tanah longsor, dan keseimbangan hayati pada wilayah Gunung Sojol yg diakibatkkan sang aktivitas eksplorasi dan eksploitasi lingkungan Gunung Sojol yang dikuasai oleh pihak yang tidak bertanggung jawab

Pemeliharaan lingkungan di pada novel pada kembali Senja karya Rifai dengan dibangunkannya cagar alam serta hutan lindung pada daerah Gunung Sojol. Penulis jua menyinggung ihwal keresahan warga akan adanya ancaman. M Rifai pada novelnya mengemas pemahaman ihwal pentingnya hubungan yg selaras antara manusia, hewan, serta mahluk dewa yg lainnya menggunakan alam, dengan hutan, menggunakan pohon di wilayahnya.

Dampak kerusakan lingkungan di dalam novel Di Balik Senja karya Moh Rifai antara lain terjadinya banjir dan tanah longsor di kawasan Gunung Sojol, kemudian flora dan fauna menjadi terganggu habitatnya

Dampak pemeliharaan lingkungan di dalam novel Di Balik Senja karya Moh Rifai yaitu, fauna lokal yaitu monyet khas Sulawesi kembali lagi hidup dengan tenang dengan adanya hutan lindung di kawasan Gunung Sojol

\section{DAFTAR PUSTAKA}

\section{SIMPULAN}


Jurnal DISASTRI (Pendidikan Bahasa dan Sastra Indonesia)

Volume 2, Nomor 3, Desember 2020| P-ISSN : 2716-4114 | E-ISSN: 2722-3329

Arikunto, Suharsimi. 2010. Prosedur Penelitian Suatu Pendekatan Praktik. Jakarta : Rineka Cipta.

Garrard, Greg. 2004. Ecocriticism. London and New York: Routledge, 2004. ISBN 0-41519672-2. Kate Rigby, Monash University.

Hermawan, S dan Amirullah. 2016. Metode Penelitian Bisnis Pendekatan Kuantitaif dan Kualitatif. Malang: Media Nusa Creative, Cetakan Pertama.

Moleong, Lexy J. 2013. Metodologi Penelitian Kualitatif (edisi revisi). Bandung: PT Remaja Rosdakarya

Tarigan, Henry Guntur. 2011. Prinsip-prinsip Dasar Sastra. Bandung: Angkasa

Teeuw, A. 2013. Sastra dan Ilmu Sastra: Pengantar Teori Sastra. Jakarta: Pustaka Jaya 